\title{
Electrical Engineering Freshmen Practicum
}

\author{
Professor Robert J. Bowman \\ Head, Department of Electrical Engineering \\ Rochester Institute of Technology \\ Rochester, New York 14623
}

Overview

The Electrical Engineering Department at Rochester Institute of Technology has developed a one-credit, experiential course called Electrical Engineering Freshmen Practicum. The course material evolved over a summer session with several incoming freshmen electrical engineering students. The course has been introduced into the curriculum in the winter quarter 2002-2003 with ten sections of sixteen students. The following topics will be addressed in this paper:

- Background and motivation for the development of the course

- Primary and philosophical objectives for the course development

- Course structure and implementation

- Assessment strategy for measuring the impact of the course

Background and Motivation

Rochester Institute of Technology (RIT) is a private university that offers a five-year, ABET accredited, program in Electrical Engineering. The first two years of the program are similar to many college programs and are rich in mathematics and the physical sciences. The last three years of the program consists of six quarters of academic work intertwined with five quarters of co-op experience. The degree requirements are met by completing 197 quarter credit hours. At this credit level any revisions to the curriculum must not increase credit requirements.

The Electrical Engineering Undergraduate program at RIT is highly regarded ${ }^{1}$ and attracts students who are well prepared in an academic sense with most incoming students having taken AP Chemistry, AP Calculus and AP Physics in high school. However, a significant percentage of electrical engineering students struggle with the first two years of college work. The rigorous and theoretical coursework demands of mathematics and the physical sciences in the first two years of undergraduate electrical engineering education provide little time for personal exploration and real-world engineering practice. Many students, who were attracted to the profession because of hands-on experiences with electronics or the perception that engineers build things, become frustrated because of little opportunity for practicing the profession. Based on this stilted view of electrical engineering, first and second year students often decide that electrical engineering is not for them.

Female engineering students comprise about $15 \%$ of the incoming engineering students but only $9 \%$ of the electrical engineering students. We have noticed, however, that women electrical engineering students have a much higher graduation rate than the general electrical engineering student population. Studies have shown both attraction and retention of women and minorities increase substantially with introduction of courses with hands-on experience. ${ }^{2,3}$ These reports indicate that the high attrition rates are due to the lack of pre-college experience in tinkering with 
physical objects. A pilot study conducted by the Principal Investigator with two incoming (freshmen) women engineering students suggests that women without pre-college experience can be very successful in an electrical engineering laboratory setting if the experience is hands-on and involves personal exploration. It also became clear that their perception of what electrical engineers do was changed to the point where they would consider electrical engineering as a viable career option.

Undeclared engineering students make up about 20\% (about 100 students) of the incoming class at RIT. These students have comparable academic credentials to the general engineering student population. The College of Engineering offers five engineering programs (Computer, Electrical, Mechanical, Microelectronic, and Industrial) and Electrical Engineering usually attracts less than $15 \%$ of these students. Freshmen and sophomore experiential courses, which are viewed as not requiring a major time investment, would allow the undeclared student to sample the real domain of the practicing electrical engineer, would improve their early career selection process, and entice a few more to commit to electrical engineering.

Transfer students usually enter the program in their second or third year. Early courses, which include standard, prerequisite, laboratory practice material such as knowledge of laboratory procedures, CAD tools, safety guidelines and keeping a laboratory notebook, also provide an easy path for transfer students to become calibrated to the new program.

Retention of freshmen electrical engineering students at Rochester Institute of Technology (RIT) has ranged from $70-75 \%$ for first year students and $62-66 \%$ for second year students over the past five years. The retention problem is evident in engineering disciplines at many universities nationwide and efforts have been focused on enriching the freshmen programs with hands-on experiences. $^{4-7}$ Electrical engineering programs have reported remarkable success by introducing courses in the freshmen year that emphasize hands-on experience., ${ }^{4,5,8}$

Some electrical engineering students at RIT are focused and highly motivated. Many of these students benefited from engineering career development opportunities available in high schools, such as Project Lead-the-Way ${ }^{9}$, enabling them to make informed career choices. Previous practical experience in electronics is also highly correlated to student success at RIT. In interviews with first year, Dean's List, electrical engineering students at RIT, it was found that the majority $(60 \%)$ of these students were building, "tinkering", or reverse engineering electronic circuits (radios, guitar amplifiers, stereos, computers, etc.) before beginning their college careers. Reverse engineering and redesign are powerful incremental learning tools and are usually the first exposure to design. ${ }^{10}$ Novel learning techniques developed in freshmen electrical engineering laboratory courses should migrate easily to high school education programs because the students will have similar backgrounds.

Electronics has proven to be an ideal vehicle for learning new concepts in many engineering disciplines. ${ }^{11,12,13}$ In electrical engineering, electronics can play a dominant role in early learning and inspiration. The excitement of personal exploration and building a functioning electronic circuit motivates one to overcome the limitations imposed by a lack of formal training. ${ }^{8,14,15}$ It is this "design" attribute that allows engineering to build on and bring context to the foundation college courses in mathematics and physical science.

"Proceedings of the 2003 American Society for Engineering Education Annual Conference \& Exposition Copyright (C) 2003, American Society for Engineering Education” 
The selection of a reference text for an introductory laboratory course is a challenge. One must be careful not to choose a companion text that merely shifts the teaching of complex electronic principles such as transistor modeling or phasor notation into the freshmen year. Texts like " $\mathrm{A}$ First Lab in Circuits and Electronics" by Tsividis are intended for second or third year students and supplement the theory already presented in class. ${ }^{16}$ A Practicum reference text must explain by analogy because of the limited practical background of most students and should be careful not to overload the student with unnecessary detail. Just-in-time and just-enough theory should be the philosophical style of the course and the text. The use of color in the reference text will increase the publication cost but would simplify the understanding of important concepts, such as the resistor color code, and bring life to laboratory photographs depicting oscilloscope waveforms, simulation plots, electronic circuits schematics, and instrument connections.

The use of computer-aided-design (CAD) tools and programming languages is now an essential part of many undergraduate courses in electrical engineering. CAD tools for schematic capture (Orcad@ , Artist $\odot$, etc.), circuit simulation (Spice, Spectre $@$, etc.), and systems analysis (MATLAB@), MathCAD(C) are now considered standard tools in electrical engineering education ${ }^{17,18,19}$ and design practice. ${ }^{20,21}$ Students must learn the use of CAD tools early in the curriculum so that subsequent courses benefit from their use. Engineering methods rely heavily on the use of the computers and scientific programming languages. However, the CAD tools and programming languages themselves do not warrant dedicated courses for the purpose of learning their use.

RIT has implemented studio style classrooms within the Electrical Engineering Department, similar in function to those at Rensselaer Polytechnic Institute (RPI). This arrangement combines lecture, recitation, computer, and laboratory activities in one "studio" facility and provides the opportunity to adopt a hands-on approach to teaching electronics and circuits. ${ }^{22,23,24}$ The rooms are also equipped with multimedia systems, 100 base-T Ethernet connections, and IEEE 488 control of instruments to enable virtual laboratory approaches such as web-based interactive learning modules. ${ }^{25}$ The studio classroom arrangement and related pedagogical style combine to form a very effective teaching environment for introductory design-oriented courses. $^{26}$

The Accreditation Board for Engineering and Technology (ABET), through their Engineering Criteria 2000 (EC2000), has prompted engineering programs to incorporate capstone project engineering courses in their programs. ${ }^{27}$ Early design experiences in the curriculum prepare the student with the tools and laboratory practice for more meaningful senior capstone projects. Six of the EC2000 criteria appear to be logical goals for the Practicum course, albeit at an introductory level.

- Ability to apply knowledge of mathematics, science, and engineering.

- Ability to design and conduct experiments as well as analyze data.

- Ability to identify, formulate, and solve engineering problems.

- Ability to use techniques, skills, and modern engineering tools necessary for engineering practice.

- Ability to communicate effectively through written means.

- Possess an understanding of professional and ethical responsibility. 
Any first course in electronic design must bear the responsibility for introducing the student to proper laboratory procedures such as soldering components and stripping wire, the use of electronic instrumentation, the identification of electronic components, keeping a laboratory notebook, and requiring the student to acknowledge that they understand the laboratory safety guidelines. The Electrical Engineering Faculty at RIT fully supports course development and course integration that introduces the student to standard laboratory practices and CAD tools early in the program, and provides early design experience. The faculty also believes that such students will be more motivated in the classroom and be better prepared to complete a significant Senior Project.

In summary, it is vitally important that the Electrical Engineering program at RIT provides first year students with a course for hands-on learning and to do so without requiring additional course load to the program (an equivalent number of credit requirements will be removed elsewhere in the program). This course must present a low barrier for entry to enable undeclared students to sample Electrical Engineering. The real challenge, in the development of Freshmen Practicum course, is to maintain a stimulating, design environment while introducing the use of CAD tools and a programming language, requiring written technical communication, engraining in the student a knowledge of laboratory procedures and safety guidelines, and addressing the ethical responsibility of electrical engineers. The key is to introduce these ancillary objectives on an as-needed basis during the ten-week design experience but keep the hands-on activity as the central focus.

Primary (tangible) objectives

- The Practicum courses will improve retention rate of first year and second year electrical engineering students.

- The Practicum course will improve attraction of female electrical engineering students.

- The Freshman Practicum course will introduce required laboratory procedures and safety guidelines.

- In the Freshman Practicum course the student will build a functioning circuit using a prototype board and through-the-hole printed circuit solder methods.

- In the Sophomore Practicum course the student will build a functioning circuit using a prototype board and automated surface mount technology.

- The Practicum courses will provide an easy (preferably one credit course) way for undeclared engineering students to sample Electrical Engineering as a career choice. This may also provide a path for non-engineering majors to sample the discipline.

- The Practicum courses will require technical report writing in the form of a laboratory notebook.

- The Practicum courses will introduce the use of CAD tools for schematic capture and simulation, systems analysis, and scientific programming.

- The Practicum courses will use studio style classroom format and dedicate a studio laboratory space to first and second year Electrical Engineering students, creating a laboratory haven for new students.

- The Practicum courses will eliminate or greatly minimize homework requirements and adopt a simple grading policy.

"Proceedings of the 2003 American Society for Engineering Education Annual Conference \& Exposition Copyright (C) 2003, American Society for Engineering Education” 


\section{Philosophical Objectives}

- The Practicum courses will excite freshmen and sophomore students about Electrical Engineering through hands-on learning, design exploration, and reverse engineering.

- The Practicum courses will reinforce exploratory learning and confidence by building on previous experience.

- The Practicum courses will promote mentoring of freshmen and sophomore students by faculty and upper division students.

- The Practicum courses will connect freshmen students with their faculty advisors in the course as scheduling permits.

- The Practicum courses will improve early, career decision-making by Electrical Engineering students and Undeclared Engineering students.

- The Practicum courses will begin acquainting the student with the importance of Electrical Engineering ethics.

Practicum Course Structure and Implementation

The course content for Electrical Engineering Freshmen Practicum was developed in a pilot study in the summer of 2002. The course material is centered around a low cost, battery operated, fully functional, Wein bridge oscillator circuit, which is sufficiently challenging for a ten week period, is easily decomposed into smaller sections for understanding first principles, self-generates interesting waveforms, and can be prototyped in one three-hour session. The student can take the design project home upon completion of the course.

The Wein bridge oscillator circuit is constructed by each student on a prototyping board. A printed circuit board (PCB) version of the circuit is built using manual soldering methods with through-the-hole components. The printed circuit board is designed to house an audio speaker, battery compartment, and circuit prototyping area, in addition to providing the oscillator circuit. When powered on, the circuit generates an audible tone of $2800 \mathrm{~Hz}$ and lights a light-emittingdiode (LED). The PCB requires no external power supply or signal generator for normal operation. A circuit prototyping area, on the PCB layout, is used by the student to explore new circuit ideas that are introduced during the last week of the course. Each student receives a low cost design kit that contains all the electronic parts and board components required for the course. Figure 1 shows top and bottom views of the populated, Wein bridge oscillator, printed circuit board.

EE Freshmen Practicum is configured to meet once a week for three hours for a ten-week quarter. The only homework assigned is to review the material before coming to class. Each student is required to attend the classes, complete the laboratory exercises, and keep a laboratory notebook similar in style to that in Slutsky and Messaros's excellent electronics lab text Introduction to Electrical Engineering Laboratories, Chapter One 'Report Writing'. ${ }^{28}$ Faculty are assigned sections with their Freshmen advisees, thus simplifying Freshmen advising.

The Practicum course is based on a studio style format. This course is offered in a studio laboratory that is devoted to the exclusive use by freshman and sophomore Electrical Engineering students. Individual lockers, located in the Practicum lab are assigned to each student to store their electronic projects and parts kit. 


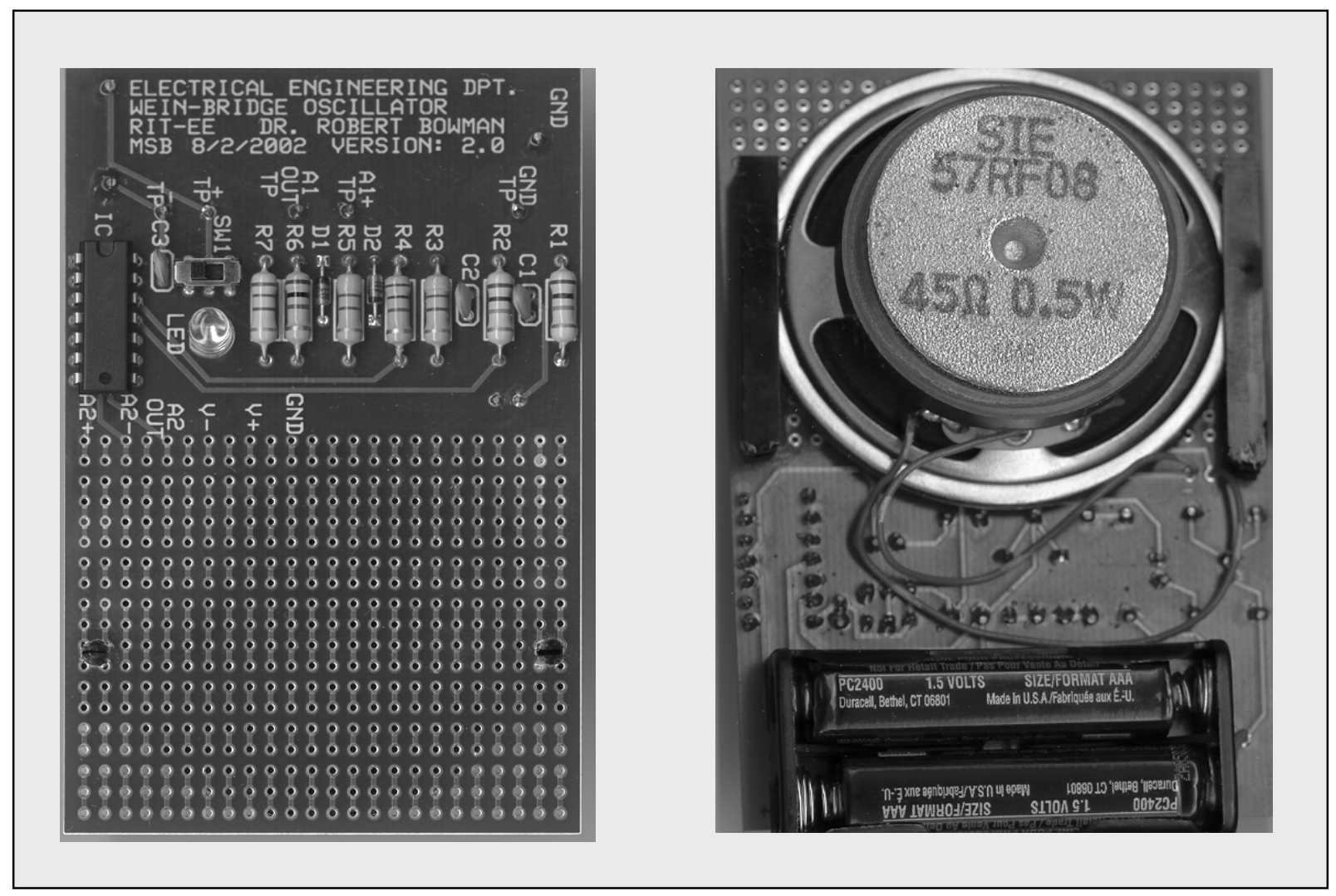

Figure 1 Top and Bottom Views of the Wein Bridge Oscillator Printed Circuit Board

A consistent pedagogical style is adopted for introducing new material: just-in-time and just enough. Some course material may be considered advanced for Freshmen Electrical Engineering students but the need for the new material is apparent in studying the circuit behavior. The project circuit architecture, introduced in the first week, is used in every exercise so that students continue to build on previous knowledge in a familiar circuit setting.

CAD tools are incorporated into the course content for schematic capture, circuit simulation, and systems analyses. Adequate computer and CAD tool resources are scheduled for this course (150 students in a quarter). Reference and data files for the laboratory exercises are placed in shared computer files that are accessed from a central server.

A Practicum reference text is published by John Wiley and Sons. The text includes:

- The operation, construction, and analysis of the electronic project

- The introduction of theory and first principles as needed

- The use of CAD tools and through-the-hole printed circuit board technology

- Laboratory procedures and electronic component identification

- Laboratory safety guidelines acknowledgement

- Ten laboratory exercises

- IEEE Code of Ethics

- A sample lab notebook write-up for one exercise

"Proceedings of the 2003 American Society for Engineering Education Annual Conference \& Exposition Copyright (C) 2003, American Society for Engineering Education"” 
Freshmen Practicum students are mentored by upper division engineering students from Engineering House (an engineering student specialty dormitory at RIT). Engineering House students volunteer to mentor students, during the evening hours, in the Practicum laboratory.

\section{Course Assessment}

The impact of these courses will be measured in terms of registration data detailing EE student retention, instructor feedback, advanced standing student mentor reports, student course evaluations, and freshmen and sophomore student interest in EE discipline related activities (participation in IEEE, Radio Science, Electronics, or Robotics Clubs). The assessment will follow the design attribute framework presented in Safoutin's et.al. paper for evaluating curriculum and assessing student learning of design knowledge skills. ${ }^{29}$ The design attribute framework was developed as part of a project to identify assessment methods that could be used by engineering programs to meet the requirements of the aforementioned ABET EC-2000 accreditation standards. Our intent is to follow up with a paper in 2004 reporting the assessment.

\section{Summary}

Electrical Engineering Freshmen Practicum provides hands-on experience and introduces the students to computer-aided-design (CAD) tools, fabrication technologies, programming methods, and electrical engineering laboratory practice that will serve them throughout their academic and professional careers. More importantly the hands-on exercises serve to stimulate the curiosity of the developing mind, bring relevance to the theoretical training in the classroom, provide a practical foundation for significant senior capstone projects, and fire the passion for this profession.

\section{References}

[1] US News \& World Report, America's Best Colleges, 2003. Best Undergraduate Engineering Programs http://www.usnews.com/usnews/edu/college/rankings/brief/engineering/nophd/enns06 brief.php

[2] J. M. Henderson, et.al., "Building the Confidence in Women Engineering Students with a New Course to Increase Understanding of Physical Devices", Journal of Engineering Education, October, 1994, pp. 1-6.

[3] R. Felder, et. al., "A Longitudinal Study of Engineering Student Performance and Retention. III. Gender Differences in Performance and Attitudes", Journal of Engineering Education, April 1995, pp. 151-163.

[4] H. C. Patangia, "A Novel Course To Provide Electrical Engineering Experience To Freshmen Students," Proc. of 2002 ASEE Annual Conference \& Exposition

[5] S. Reyer, G. Wrate, J. Wheeldon, and O. Petersen, "Freshman Electrical Engineering Course Addressing Retention and Career Choice," Proc. 2002 ASEE Annual Conference \& Exposition

[6] G. Tryggvason, M. Thouless, D. Dutta, S.L. Ceccio, and D. M. Tilbury, "The New Mechanical Engineering Curriculum at the University of Michigan," Journal Engineering Education of, July 2001

[7] D. J. Newman, A.R. Amir, "Innovative First Year Aerospace Design Course at MIT." Journal of Engineering Education, July 2001

[8] L.R. Carley, P. Khosla, and R. Unetich, "Teaching "Introduction to Electrical and Computer Engineering" in Context," Proc. of IEEE, Vol., 88, No. 1, January 2000 
[9] G. Johnson, National Training Director, RIT, "Project Lead-the-Way”, Fully-developed Science and Engineering Curriculum for High School and Middle School, http://www.pltw.org/

[10] K.L. Wood, D. Jensen, J. Bezdek, and K. Otto, "Reverse Engineering and Redesign: Courses to Incrementally and Systematically Teach Design," Journal of Engineering Education, July 2001

[11] M. Rupnik, F. Runovc, and M. Kordas, "The Use of Equivalent Electronic Circuits in Simulation Physiological Processes," IEEE Transactions on Education, vol. 44, No. 4.November 2001

[12] L.M. Head, G. Canough, and R. P. Ramachandran, "Real-World Design as a One-Semester Undergraduate Project: Example of a Robust and Low-Cost Solar Lantern," IEEE Transactions on Education, Vol. 45, No. 4, November 2002

[13] R. Kuc, "Teaching the Nonscience Major: EE101-The Digital Information Age," IEEE Transactions on Education, Vol. 44, No. 2, May 2001

[14] D.J. Comer, "Teaching MOS Integrated Circuit Amplifier Design to Undergraduates," IEEE Transactions on Education, vol. 44, No. 3, August 2001

[15] S. M. Lord, “Optoelectronics Experiments for First -Year Engineering Students," IEEE Transactions on Education, vol. 44, No 1, February 2001

[16] Y. Tsivdis, "A First Lab in Circuits and Electronics," John Wiley \& Sons, 2002

[17] M.T. Abuelma'atti and I.S. Qamber, "Applications of SPICE Simulation Software to the Study of Reliability and Availability in Electrical Engineering Education," IEEE Transactions on Education, Vol. 45, No. 3, August 2002

[18] W. E. Dixon, D.M. Dawson, B.T. Costic and M.S. de Queiroz, "A MATLAB-Based Control Systems Laboratory Experience for Undergraduate Students: Toward Standardization and Shared Resources," IEEE Transactions on Education, Vol. 45, No. 3, August 2002

[19] J. Attia, PSPICE and MATLAB for Electronics, An Integrated Approach, CRC Press, Boca Raton, Fla., 2002, ISBN 0-8493-1263-9

[20] Discussions with the RIT Electrical Engineering Department Industrial Advisory Board, May 2002.

[21] J. Lang, "Industry Expectations of New Engineers: A Survey to Assist Curriculum Designers, Journal of Engineering Education, January, 1999, pp. 43-51.

[22] E. W. Maby, A. B. Carlson, K. A. Connor, W. C. Jennings, and P. M. Stoch, "A Studio Format for Innovative Pedagogy in Circuits and Systems", $31^{\text {st }}$ ASEE/IEEE Frontiers in Education Conference, October 2001

[23] A. Carlson, W. Jennings, and P. Schoch, "Teaching Circuit Analysis in the Studio Format: A Comparison with Conventional Instruction", 31 $1^{\text {st }}$ ASEE/IEEE Frontiers in Education Conference, October 2001.

[24] J. McNeil and K. Keenaghan, "Transitioning an Engineering Course to Studio Format", $32^{\text {nd }}$ ASEE/IEEE Frontiers in Education Conference, November 2002.

[25] D. Millard and G. Burnham, "Innovative Interactive Media for Electrical Engineering Education", $31^{\text {st }}$ ASEE/IEEE Frontiers in Education Conference, October 2001

[26] ] P. Little and M. Cardenas, "Use of "Studio" Methods in the Introductory Engineering Design Curriculum," Journal of Engineering Education, July 2001

"Proceedings of the 2003 American Society for Engineering Education Annual Conference \& Exposition Copyright (C) 2003, American Society for Engineering Education" 
[27] "Criteria for accrediting engineering programs," Accreditation Board for Engineering and Technology, Baltimore, MD, 2000

[28] E. B. Slutsky and D. W. Messaros, "Introduction to Electrical Engineering Laboratories, Circuits Electronics, \& Digital Logic," Chapter 1 Report Writing, Prentice-Hall, 1992

[29] M.J, Safoutin, C.J, Atman, R. Adams, T. Rutar, J.C. Kramlich, and J.L. Fridley, “A Design Attribute Framework for Course Planning and Learning Assessment," IEEE Transactions on Education, Vol. 43, No. 2, May 2000

ROBERT J. BOWMAN received the B.S.E.E. degree from Penn State Univ., the M.S.E.E. degree from San Jose State Univ., and the Ph.D.E.E. degree in 1980 and Ph.D.Bioeng in 1983 from the Univ. of Utah. He has practiced as a design engineer for thirty-two years and has held faculty positions at the Univ. of Utah, Univ. of Vermont, Univ. of Rochester, and is currently Department Head of Electrical Engineering at Rochester Institute of Technology. 